\title{
Retomando el camino de las publicaciones científicas en la Escuela de Enfermería en Valparaíso...
}

Autores:

Nidia Núñez Alvarado. Enfermera, Magíster en Salud Pública, Profesora Emérita Escuela de Enfermería, Universidad de Valparaíso. E-mail: nidia.nunez@uv.cl

Angélica Mosqueda-Díaz. Enfermera-Matrona, Doctora en Enfermería, Académica Escuela de Enfermería, Universidad de Valparaíso. E-mail: angelica.mosqueda@uv.cl

Las/as enfermeras/os siempre han mantenido un interés por comunicar en qué consiste la aplicación del cuidado de enfermería, realizado por profesionales en distintas áreas y a través de todo el curso de la vida de las personas (1). Una revista, es un instrumento que permite satisfacer este interés, especialmente en una institución formadora de profesionales.

Como respuesta a esta situación, a comienzo de la década de los sesenta, en la Escuela de Enfermería "Carlos Van Buren" se gestó la creación de la primera revista nacional, del ámbito profesional (2). En dicha revista participaban docentes, con artículos originales que mostraban el quehacer de enfermería y aspectos curriculares relevantes, además se estimulaba a los estudiantes a escribir sus experiencias e inquietudes a cerca de la profesión.

La confección de la revista significaba un esfuerzo agregado a las responsabilidades universitarias, ya que incluía no solo elaborar y preparar el material a publicar, sino también el trabajo de im- presión y la confección física de cada ejemplar. Lo anterior implicaba, además, la colaboración del personal administrativo de la Escuela, lo cual reflejaba la motivación y el compromiso de "todos" con esta revista.

La distribución de la revista se realizaba con la cobertura más amplia posible, así, se enviaban impresos al Colegio de Enfermeras y a los Servicios de Salud regionales, en especial a aquellas unidades que eran utilizadas como campos clínicos. Asimismo, se enviaban algunos ejemplares a las otras Escuelas de Enfermería del país, con la finalidad de compartir información actualizada sobre el cuidado y mejorar la formación profesional.

La revista se publicó en forma semestral por casi una década. Sin embargo, debido a la reforma universitaria, intensificada hacia fines del año 1967, las energías debieron concentrarse en participar en este proceso $y$, sobre todo, en realizar una sustentada justificación de Enfermería como Disciplina, lo que en ese tiempo se definió como 
la existencia de un método propio para evaluar los fenómenos. Con todo, la publicación de la revista debió descontinuarse.

La idea de retomar el camino de las publicaciones se mantuvo latente por mucho tiempo, siendo a mediados del año 2015, donde un par de académicas jóvenes, plantean la inquietud de desarrollar un proyecto que tendría por objetivo concretar la implementación de una revista científica para la disciplina de Enfermería, proyecto que fue respaldado por todo el cuerpo académico y las autoridades de la Escuela.

Así, surgió un intenso trabajo para dar forma a las políticas editoriales y la estructura que se encargaría de dar forma y continuidad a este proyecto. Se trataría de una revista científica, arbitrada, desarrollada en un formato digital, más acorde a los nuevos tiempos y que permitiera una difusión más amplia de su contenido, con la proyección de ser indizada en diferentes bases de datos a corto y mediano plazo.

Para dar sustento a este proyecto, se invitó a un destacado grupo de enfermeras y enfermeros, a nivel internacional y nacional, para ser parte del Comité editorial, obteniendo grandes muestras de apoyo, que representaron un significativo impulso a esta iniciativa.

Además, con la finalidad de ampliar la participación e involucrar a las futuras generaciones de profesionales, se solicitó la contribución de los/ as estudiantes, con su creatividad, en los aspectos relacionados al diseño de la revista. Como es costumbre, la respuesta positiva no tardó en llegar, generando una alta convocatoria, de la cual se seleccionaron las siguientes alternativas:

Nombre: Benessere Revista de Enfermería, cuyo significado es bienestar en italiano, lugar de nacimiento de Florence Nightingale.
- $\quad$ El logo de la revista, incluye los colores institucionales de la Universidad de Valparaíso y la cruz del sur, que esperamos nos oriente tal como lo ha hecho con la Universidad.

La portada, muestra la imagen de Nightingale, unas manos que representan el cuidado como centro de interés de la disciplina y la lámpara que caracterizó el trabajo realizado en la guerra de Crimea y que significó para Enfermería ser reconocida como profesión.

Benessere, Revista de Enfermería se ha propuesto publicar manuscritos derivados de investigaciones, reflexiones y experiencias de cuidado. Con la difusión y transferencia de este conocimiento se espera visibilizar el quehacer de Enfermería y fortalecer la "Gestión del Cuidado"(3).

Todo lo expresado solo será posible con la utilización de esta nueva iniciativa de divulgación científica disciplinar, tanto enviando sus contribuciones como aplicando la evidencia publicada, por lo que extendemos la invitación a los/as profesionales de enfermería y áreas afines a ser parte de ella...

\section{Referencias bibliográficas}

1. Beltrán O. Factores que influyen en la interacción humana del cuidado de enfermería. Invest educ enferm. 2006; 24(2): 144-50.

2. Escuela de Enfermería Carlos Van Buren. Revista de la Escuela de Enfermería "Carlos Van Buren". 1962; 1(1): 3-5.

3. Subsecretaria de Redes Asistenciales, Departamento de Asesoría Jurídica. Aprueba norma general administrativa № 19, "Gestión del cuidado de Enfermería para la Atención Cerrada". [en línea] 2007. [fecha de acceso 20 de abril 2011]. Disponible en: http:// www.colegiodeenfermeras.cl/index. php?option=com_k2\&view=item\&id=89: 